\title{
Penguatan Karakter Anggota 'Aisyiyah Melalui Penyuluhan Nilai-nilai Hijrah Rasulullah
}

\section{Strengthening the Character of Members 'Aisyiyah through Extension of the Values of the Migration of the Prophet}

\author{
Casmini
}

UIN Sunan Kalijaga Yogyakarta, Yogyakarta, Indonesia casmini@uin-suka.ac.id

Riwayat Artikel: Dikirim; Diterima; Diterbitkan

\begin{abstract}
Abstrak
Penguatan karakter melalui penyuluhan nilai-nilai hijrah Rasulullah dilaksanakan sebagai bentuk respon PP 'Aisyiyah Majelis Tabligh terhadap dinamika globalisasi dalam upaya menuju anggota 'Aisyiyah yang tidak phobi dan mempunyai daya tahan terhadap negative impact dari perkembangan teknologi informasi. Penguatan nilai-nilai karakter ini dilaksanakan melalui penyuluhan dengan model pengajian pada pengajian bulanan di bulan Oktober 2019. Hasil penguatan menunjukkan bahwa peserta penyuluhan memahami nilai-nilai hijrah Rasulullah yang melandasi kuatnya karakter personal dan sebagai anggota organisasi 'Aisyiyah dalam mengembangkan dakwah. Implementasi nilai-nilai karakter hijrah Rasulullah perlu tindak lanjut pelatihan yang lebih intensif pada pimpinan ranting 'Aisyiyah masing-masing.
\end{abstract}

Kata kunci: penguatan karakter, nilai-nilai hijrah Rasulullah, dinamika globalisasi, penyuluhan

\begin{abstract}
Strengthening the character through the promotion of the values of the Prophet's migration was carried out as a responsive form of PP 'Aisyiyah Tabligh Assembly to the dynamics of globalization in an effort to member' Aisyiyah who is not a phobia and has resistance to the development of information technology but still bolds firmly the values of the hijrah experienced by Rasulullah . Strengthening these character values is carried out through counseling with the recitation model in the monthly recitation in October 2019. The reinforcement results show that the counseling participants understand the values of the Prophet's migration which underlies the strength of personal character and as a member of the isy Aisyiyab organization in developing da'wah. Implementation of character values need to follow the Prophet migrated more intensive training on leadership twig 'Aisyiyah respectively.
\end{abstract}

Keywords: strengthening the character, the values of the Prophet's migration, the dynamics of globalization, counseling

\section{PENDAHULUAN}

Penguatan karakter merupakan hal yang urgen dalam mensikapi dinamika global. Perkembangan sains yang terus bergulir telah menembus ke semua penjuru, hingga daerah terpencil sekalipun. Media TV dan internet sudah dijumpai dalam setiap detik kehidupan manusia saat ini, hingga kebutuhan informasi dalam sekejap akan didapat.

Pada sisi lain, umat Islam saat ini mendapatkan citra yang kurang bagus di mata dunia. Kesan sebagai umat yang hinadina, terbelakang dan mudah diperdaya seakan melekat yang menunjukkan bahwa Islam adalah agama yang tidak kontekstual dengan perkembangan zaman. Kesan sebagai agama yang menakutkan, label teroris serta ekstrim dan eksklusif cukup menyudutkan bagi Islam.

Saat ini, Muhammadiyah diuji ketangguhannya sebagai gerakan Islam yang membawa misi ideologi reformisemodernisme yang berkemajuan dengan 
tetap berpegang pada al-Quran dan alHadits. Muhammadiyah dihadapkan pada masalah dan tantangan baru keumatan dan kemanuasiaan yang semakin kompleks. Muhammadiyah dengan tidak menanggalkan ideologis dituntut untuk mampu menghadapi derap kehidupan dan menjawab tantangan serta masalah era global. Allah berfirman dalam Al-Qur'an yang artinya:

"Hai orang-orang yang beriman, bertakwalah kepada Allah dan hendaklah setiap diri memperhatikan apa yang telah diperbuatnya untuk hari esok (akhirat); dan bertakwalah kepada Allah, sesungguhnya Allah Maha Mengetahui apa yang kamu kerjakan (Q.s. Al-Hasyr [59]: 18)".

Salah satu yang mendesak untuk diperhatikan adalah kekokohan karakter personal maupun organisasional yang secara istiqomah harus diperjuangkan. Karakter secara bahasa adalah kualitas mental, moral, atau kekuatan moral. Secara terminologis karakter adalah kualitas individu dalam berpikir, berperilaku dan menjalin bekerjasama baik dalam lingkup keluarga, sosial masyarakat dan negara (Doni Koesoema, 2010). Definisi ini menekankan pada daya survival dan resilensi personal dan organisasional menjadi kekhasan yang harus dimilikinya.

Secara riil, Islam adalah agama yang membawa rahmah bagi seluruh alam yang menghantarkan menuju kesejahteraan dan terkandung ajarannya menempatkan sandaran pada Allah SWT yang di dalamnya memuat karakter yang harus diimplementasikan oleh umat Islam dalam bukti nyata perilaku. Kuatnya karakter dalam ajaran Islam, salah satunya adalah perilaku hijrah Rasulullah dari Makkah ke Madinah yang mampu membangun peradaban yang tinggi.

Penegakan sistem ajaran Islam yang dilamnya memuat aqidah (keyakinan), syariah (aturan-aturan hukum peribadahan dan muamalah) serta akhlak (karakter) bersinergi membentuk tegaknya peradaban manusia di muka bumi.

Kekokohan pondasi aqidah melandasi terwujudnya syariah dan akhlak. Ditegaskan oleh Marzuki (2011:468) bahwa syariah diibaratkan sebagai wujud bangunan yang perlu dirawat melalui implementasi aqidah yang benar akan mengarahkan pada pencapaian akhlak (karakter) yang seutuhnya (Marzuki, 2011:468). Sinergitas antara aqidah, syariah dan akhlak dibutuhkan dalam upaya penegakan karakter muslim di era saat ini.

Akhlak (karakter) dihasilkan dari terwujudnya bangunan syariah yang benar yang dilandasi oleh pondasi aqidah yang kokoh. Tanpa aqidah dan syariah tidak akan terwujud akhlak (karakter) yang sebenarnya.

Semangat perjuangan K.H. Ahmad Dahlan yang mengedepankan aqidah, syariah dan karakter dilakukan untuk membangun kebangkitan kesadaran baru agar masyarakat memiliki keyakinan diri untuk melakukan perubahan dirinya. Penemuan identitas diri dan penanaman keyakinan diri merupakan modal dasar dalam melawan kemungkaran dan menegakkan kebaikan (Sodiq A. Kuntoro, 2006:138). Kedua modal dasar (kejelasan identitas diri, keyakinan diri) dapat menstimulasi spirit dalam menjalankan Islam yang sebenar-benarnya.

Perjuangan K.H. Ahmad Dahlan relevan dengan spirit hijrah Nabi dari Mekah ke Madinah. Hijrah Nabi mencontohkan keteguhan niat, ikhtiar yang sungguh-sungguh, pengorbanan, ketahanan diri, kebulatan tekad, kesabaran dan keihlasan dalam berjuang melawan kemungkaran. Tulisan ini memaparkan hasil kegiatan pengajian bulanan PP 'Aisyiyah Majelis Tabligh tentang nilai-nilai psikologis perjuangan hijrah Rasulullah untuk dijadikan refleksi penguatan karakter dalam konteks era global. Pimpinan Pusat 'Aisyiyah Majelis Tabligh berikhtiar merespon fenomena baru di abad modern dengan melaksanakan penyuluhan melalui 
pengajian rutin bulanan. Pengajian bulan Oktober 2019 mengambil tema "Kontekstualisasi nilai-nilai hijrah Rasulullah dalam penguatan karakter muslim".

\section{METODE}

Kegiatan penyuluhan ini pada dasarnya merupakan kegiatan yang dilaksanakan oleh PPA Majelis Tabligh dengan pemateri penulis. Pelaksanaan penyuluhan dilakukan dengan model pengajian rutin dan pada bulan Oktober 2019 bertemakan "Kontekstualisasi nilai-nilai hijrah Rasulullah dalam penguatan karakter muslim". Kegiatan pengajian bulanan di bulan Oktober merupakan bagian dari Gerakan Perempuan Mengaji yang dilaksanakan pada Sabtu 28 September 2019 di Aula Kantor Pimpinan Pusat 'Aisyiyah Jl. KHA Dahlan No. 32 Yogyakarta. Pada dasarnya pengaiian rutin dari bulan januari hingga Desember dari Gerakan Perempuan Mengaji (GPM) telah disusun tema secara keberlanjutan dari tahun sebelumnya, sehingga tema pengajian tidak tumpeng tindih dari pengajian antar bulannya dan konteks sesuai dengan kebutuhan masyarakat.

Peserta penyuluhan adalah anggota dan simpatisan 'Aisyiyah dan Muhammadiyah yang berada di Yogyakarta. Pada bulan Oktober peserta yang mengikuti berjumlah 57 anggota 'Aisyiyah dari Bantul, Sleman dan Kota Yogyakarta. Model penyuluhan berbentuk pengajian dengan metode interactive-lecturing dan layanan bimbingan personal. Pengaiian dilaksanakan pada awal sesi untuk memberikan materi tentang kontektualisasi nilai-nilai hijrah Rasulullah dalam penguatan karakter muslim yang dilaksanakan selama 90 menit dari pukul 13.00-14.30. Layanan bimbingan personal dilaksanakan secara personal kepada para peserta yang menghendaki sebagai bentuk follow up dari pengajian.

\section{HASIL DAN PEMBAHASAN}

Persiapan Kegiatan

Persiapan kegiatan terbagi pada dua pembagian tugas, yaitu tugas PPA Majelis Tabligh meliputi penyediaan tempat, sarana prasarana pengajian, leaflet, dan undangan peserta serta penyediaan fasilitas live streaming. Bagi pemateri menyiapkan makalah dan slide untuk presentasi sebagai stimulasi penyuluhan.

\section{Pelaksanaan Kegiatan}

Kegiatan penyuluhan dengan kemasan pengajian bulanan dilaksanakan secara face to face dan disiarkan secara langsung melalui IG 'Aisyiyah pada Sabtu 28 Oktober 2019. Alur sesi dalam penyuluhan diawali dengan pra acara dengan membaca asmaul khusna sembari menunggu peserta regristrasi. Masuk pada acara dibuka dengan tadarus Q.S Ar Rahman dilanjutkan dengan penyampaian materi secara intekatif. Materi yang disampaikan pada acara meliputi;

\section{a. Proses Hijrah Nabi}

Salah satu sejarah Nabi yang penting bagi adalah peristiwa hijrah dari Makkah ke Madinah. Keberadaan Nabi saat di Makkah Adalah berdakwah membangun landasan aqidah dan berubah saat di Madinah berfokus pada pengembangan pilar-pilar negara dan terwujudnya pilar peradaban baru. Banyak hal penting dari pra, saat dan pasca proses hijrah. Terbentang harapan baru dengan melakukan hijrah, setelah kaum muslimin mengalami penderitaan fisik dan psikhis di Makkah. Energi positif dari hijrah memberikan kekuatan untuk bangkit dari keterpurukan dan segera mengatasi masalah serta menyadari akan kegelapan yang dialami. Salah satu kepentingan hijrah adalah pertimbangan kepentingan sosial, dari dakwah bersifat personal merambah pada aksi komunitas luas hingga terbentuk satu masyarakat bernegara. Orientasi hijrah dari seruan tentang eskatologis yang berbicara masalah-masalah harapan, pahala 
dan dosa beralih pada bahasan tatanan sosial dan budaya untuk terbentuknya peradaban Islam. Hijrah dilakukan dengan perencanaan yang matang oleh Nabi dengan mempertimbangkan berbagai hal. Kejelasan pendelegasian yang dilakukan Rasulullah kepada para sahabat dalam upaya agar proses hijrah berjalan lancar dan aman. Perencanaan yang matang dilakukan dengan mempelajari situasi pra hijrah yang mendapatkan ancaman dari kaum Quraisy. Termaktub dalam al Quran surat al-Anfal 30, yang artinya

"Dan ingatlah) ketika orang-orang kafir (Quraisy) memikirkan daya upaya terhadapmu untuk menangkap dan memenjarakanmu atau membunubmu, atau mengusirmu. Mereka memikirkan tipu daya dan Allah menggagalkan tipu daya itu, dan Allab sebaik-baik pembalas tipu daya".

Abu Jahal memilih beberapa pemuda yang berasal dari kabilah Quraisy yang diniatkan untuk membunuh Rasulullah. Pengepungan rumah Rasulullah direncanakan saat Beliau dalam kondisi tidur nyenyak. Rasulullah mengetahui rencana jahat Abu Jahal sehingga membagi tugas dengan Abu Bakar yang menemani perjalanan dan Ali bin Abi diberi tugas untuk menempati tempat tidurnya. Abu Bakar menawarkan diri kepada Rasulullah untuk menemani perjalanan, maka menyiapkan dua ekor unta lengkap dengan pelananya. Satu ekor unta ditunggangi Rasulullah dan satu ekor lagi ditunggangi oleh Abu Bakar dan puteranya 'Abd Allah.

Di saat Nabi telah dikepung, tanpa membuang waktu dengan keluar melalui jendela di belakang rumahnya tempat kedua unta yang telah disiapkan Abu Bakar. Mereka bertiga melintasi rute menuju gua di Gunung Tsur agak ke selatan, jalan kearah Yaman yang dikenal dengan nama Gua Tsur yang terletak lima kilometer dari kota Makkah. Tiga hari (Jum'at, Sabtu dan Ahad) dilalui beliau dalam persinggahan di Gua Tsur sampai menunggu situasi aman untuk melanjutkan perjalanan (Martin
Lings, 1991).

Melihat kondisi sudah tidak ada pengejaran dari orang Quraisy, Rasulullah melanjutkan perjalanan menyusuri Laut Merah dengan melewati jalan yang belum dilalui orang lain. Perjalanan Rasulullah dibuntuti oleh salah satu orang Quraisy yang bernama Suraqa bin Malik Ju'syum atas iming-iming mendapatkan hadiah 100 ekor unta. Suraqa berusaha mengejar Rasulullah dengan siap busur panahnya, namun ketika telah mendekat kuda terjerembab jatuh hingga upaya tiga kali gagal. Rasulullah sempat singgah selama empat hari di Quba sebelum tiba di Yatsrib dan dimanfaatkan untuk membangun masjid Quba sebagai masjid awal dalam sejarah Islam. Ali bin Abi Thalib beserta pengikutnya menjemput Rasulullah pada 12 Rabiul Awwal/ 622 M. Peristiwa hijrah kemudian ditetapkan sebagai tahun baru hijriyah dalam Islam dan Yastrib berganti dengan nama Madinah.

\section{b. Makna Hijrah Nabi}

Saat ini hijrah dijadikan sebagai framing untuk menunjukkan aktivitas pola perpindahan dari hidup yang negatif pada hal positif (Syarif \& Zuhri, 2019). Hijrah secara bahasa berarti perpindahan, meninggalkan, berpaling, tidak mempedulikan lagi (Ambari, 2005). Hijrah memiliki dua makna dasar, yaitu pertama bermakna berpindahnya nabi Muhammad dengan diikuti beberapa pengikutnya dari Makkah ke Madinah untuk menyelamatkan diri dari tekanan orang kafir Qurays. Kedua bermakna menyingkir untuk sementara waktu dari tempat satu ke tempat lain dengan alasan kebaikan dan keselamatan (https://kbbi.web.id/hijrah). Hijrah berarti memuat dua makna, yaitu makaniyah berarti hijrah secara tempat atau fisik dan hijrah maknawiyah adalah hijrah mental atau hijrah hati.

Konteks hijrah Rasulullah hijrah bermakna makaniyah yaitu berupaya ke luar dari tempat kafir menuju tempat mukmin, dan dalam konteks maknawiyah berarti 
berpindah dari keburukan kepada kebaikan dan dari kebatilan menuju kebenaran. Perpindahan yang dimaksudkan adalah lepas dari hal yang bersifat negatif menuju hal yang bersifat positif, yaitu melepaskan perilaku tercela dan kembali tunduk patuh kepada Allah SWT.

Ada tiga makna kandungan hijrah makaniyah, yaitu menegakkan, menjalankan dan komitmen menjalankan secara konsisten tanpa dari batas-batas yang telah ditentukan (Aswadi, 2011). Hijrah adalah menjauhkan diri dari berbagai bentuk penyimpangan menuju pada tata aturan yang sesuai nilai-nilai normatif (al Quran dan Hadits).

Berdasarkan paparan di atas, hijrah dapat dimaknai dalam formulasi normatif dan historis. Formulasi normatif menuntunkan hijrah dalam tiga aspek makna, yaitu hijrah untuk mendekatkan diri kepada Allah SWT, hijrah menjauhi larangan Allah SWT, dan hijrah dalam pengetian tidak ke luar dari ketentuan Allah (Aswadi, 2011). Hijrah dalam konteks historis merupakan proses memenuhi permintaan masyarakat Madinah yang saat berada dalam kondisi tidak kondusif karena konflik antar suku.

\section{c. Kontekstualisasi Nilai Hijrah untuk Penguatan Karakter}

Penguatan karakter adalah penguatan yang berkaitan erat dengan watak dan kepribadian seseorang. Penguatan ini harus dibangun dan dibentuk secara bertahap agar melahirkan kepribadian dan watak yang baik. Penguatan karakter adalah penguatan atribut kepribadian yang dapat atau tidak dapat diterima oleh masyarakat, meliputi kognitif, afektif dan perilaku (Ibrohim, 2016). Refleksi dari peristiwa hijrah Rasulullah, maka ada banyak karakter Rasulullah yang dicontohkan baik karakter sosial maupun karakter sosial. Sudah seyogyanya penggalian pemahaman dan pemaknaan baru hijrah Rasulullah merupakan keniscayaan yang harus dilakukan untuk menemukan kekhasan kepribadian untuk mendapatkan semangat baru dalam konteks era kekinian. Ikhtiar menuju umat berkualitas sebagaimana firman Allah dalam Q.S. Ali Imran: 110 setelah kepercayaan dibangun pada perpindahan Rasulullah ke Madinah perlu dilakukan secara kontinyu dengan mengikuti dinamika kehidupan. Hijrah Nabi Saw dari Makkah ke Madinah perlu dipahami tidak hanya secara tekstual namun perlu secara kontekstual, tidak hanya secara harfiyah namun juga jasmaniyah dan maknawiyah. Muhammadiyah sebagai organisasi gerakan tajdid yang berkemajuan harus terus melangkah beramar ma'ruf nahi mungkar dari berbagai lini kehidupan. Muhammadiyah dalam menyelesaikan problem umat dapat mengambil pelajaran dari peristiwa hijrah Rasulullah dalam membangun masyarakat Madinah yang saat itu dalam kondisi terbelakang.

Kedatangan Rasul di Madinah, yang pertama dilakukan adalah mempersaudarakan dua kelompok besar yaitu Muhajirin dan Anshor. Sejarah mencatat, bahwa Rasulullah telah membangun persatuan dan kesatuan masyarakat Madinah dalam lima belas abad yang lalu. Masyarakat Madinah yang plural, multi-etnis, multi-agama dipersatukan oleh Nabi dengan melalui ikrar Piagam Madinah. Peristiwa ini menandakan dimulainya pengenalan "hukum kota" untuk orang-rang Anshar. Gerakan Rasulullah yang kedua adalah mengeratkan tali ukhuwah antara kabilah-kabilah menuju keharmonisan hubungan persatuan. Rasulalllah melangkah tidak langsung secara revolusioner tetapi dilakukan dengan secara evolusioner (bertahap).

Dakwah Rasulullah dilakukan dengan mendasarkan pada Q.S. al Baqarah: 256, yaitu dengan tanpa paksaan. Rasulullah meyakini bahwa misi pokok agama adalah pembebasan dengan tetap memegang aturan serta misi keadilan sosial, menciptakan kesejahteraan masyarakat 
serta memberikan hak-hak kaum miskin dan kaum yang lemah.

Berdasarkan paparan di atas, dapat digambaran peta nilai-nilai karakter dalam peristiwa hijrah Nabi dari Makkah ke Madinah yang menjadi dasar karakter Muhammadiyah, yaitu:

Kontekstualisasi Nilai Hijrah Nabi

\begin{tabular}{|c|c|}
\hline Nilai Karakter Muhammadiyah & Peristiwa Hijrah \\
\hline Berpihak pada mustadl'afin dan dlu'afa & Rasulullah melindungi pengikut di Makkah dari tekanan kaum Quraisy \\
\hline Berpikiran maju & $\begin{array}{l}\text { Pasca hijrah, Rasulullah mengembangkan institusi pendidikan masyarakat } \\
\text { Madinah, yang mengajarkan membaca, menghitung dan menulis. }\end{array}$ \\
\hline Bersahaja dan sederhana & Saat harta benda ditinggal di Makkah, hanya membawa bekal secukupnya \\
\hline Bijaksana & Saat tiba di Madinah, Nabi memutuskan tinggal sesuai kemauan Unta \\
\hline Damai & Mempersaudarakan antara Muhajirin dan Ansor \\
\hline Dinamis & Bergerak dari satu daerah ke daerah lain untuk menjadi yang lebih baik \\
\hline Disiplin & Melakukan hijrah sesuai rencana \\
\hline Kasih sayang & $\begin{array}{l}\begin{array}{l}\text { Menyayangi antara Muhajirin dan Anshar, Nabi menyayangi antar } \\
\text { pengikutnya }\end{array} \\
\end{array}$ \\
\hline Kebahagiaan & Rela meninggalkan harta benda di Makkah \\
\hline Kebebasan & Terlepas dari tekanan kaum Quraisy Makkah \\
\hline Keikhlasan & Hijrah diniatkan karena Allah Swt \\
\hline Kerjasama & Bekerjasama membangun masjid Quba' \\
\hline Keseimbangan (tawasuth atau moderat) & Peristiwa hijrah mengajarkan kebersamaan \\
\hline $\begin{array}{l}\text { Keteladanan, Kejujuran, Komitmen, Kreatif, } \\
\text { Layanan }\end{array}$ & Keseluruhan peristiwa hijrah dari Makkah ke Madinah \\
\hline Loyalitas & $\begin{array}{l}\text { Sahabat setia mengikuti petunjuk Nabi, kemudian sahabat menerima } \\
\text { rumah pilihan Nabi untuk singgah di Madinah. }\end{array}$ \\
\hline \multirow{2}{*}{ Membaca } & a. Cermat membaca situasi saat keluar dari Gua Tsur \\
\hline & b. Cermat memilih jalur hijrah \\
\hline Menghargai & Piagam Madinah \\
\hline \multirow{2}{*}{ Pembaharuan (tajdid) } & a. Membangun kota Madinah (Sosial, ekonomi) \\
\hline & b. Memurnikan Tauhid dari ancaman praktek syirik di Makkah \\
\hline Percaya diri & Yakin akan bisa lolos dari hambatan kaum Quraisy \\
\hline Persatuan & Menyatukan kaum Muhajirin dan Anshar \\
\hline $\begin{array}{l}\text { Proaktif, Qanaah, Rendah hati, Sabar dan } \\
\text { bersyukur, santun, kritis, suka beramal } \\
\text { shaleh, teliti dan cermat, ulet }\end{array}$ & Keseluruhan peristiwa hijrah dari Makkah ke Madinah \\
\hline Toleransi & $\begin{array}{l}\text { Peristiwa Piagam Madinah pasca hijrah sebagai konsensus sosial yang } \\
\text { mengatur perilaku kehidupan masyarakat Madinah yang terdiri dari } \\
\text { berbagai latar belakang suku, agama, dan strata sosial. }\end{array}$ \\
\hline
\end{tabular}

Belajar dari peristiwa hijrah Nabi, kontekstualisasi untuk implementasi gerakan dakwah Muhammadiyah berkemajuan harus bersinergi antara penguatan karakter personal dan karakter organisasional serta integrasi antara keduanya. Penguatan karakter personal bermakna penguatan yang berkaitan ciriciri gambaran keadaan individu yang sebenarnya serta pembeda dengan individu yang lain. Dimensi karakter personal meliputi kepribadian, persepsi, sikap, kemampuan, kebutuhan, kepercayaan, pengalaman, dan pengharapan. Penguatan karakter organisasional berkaitan dengan karakter kepribadian seseorang dalam berhubungan dengan bagaimana hidup di organisasi dengan perannya kepada lingkungan sosial. Penguatan karakter personal dalam proses hijrah dicontohkan oleh Rasulullah SAW seperti nilai karakter keteguhan niat, ikhtiar yang sungguhsungguh, pengorbanan, ketahanan diri, kebulatan tekad, kesabaran dan keihlasan. Kandungan hijrah Nabi pada muatan pendidikan ideologi. Mulai dari 
perencanaan yang matang, perjalanan yang berliku, dan beberapa tempat destinasi hijrah yang dilandasi oleh kesucian, keteguhan hati, komitmen, keberanian serta semangat berkorban dengan resiko bermuara pada upaya perjuangan membangun dan memajukan masyarakat Madinah.

Nilai-nilai penguatan karakter organisasional dari peristiwa hijrah dicontohkan oleh Rasulullah yang memberikan kepercayaan dan tugas kepada para sahabat (Abu Bakar dan Ali bin Abi Thalib). Kepercayaan Rasulullah kepada Ali bin Abi thalib dipercaya untuk menggantikan tidur di tempat tidur Abu Bakar bertugas sebagai pemasok informasi dan melakukan monitoring orang-orang kafir Quraisy Mekah. Asma' putri Abu Bakar berperan menyiapkan logistik dan semua bekal perjalanan dari tempat transitnya di Gua Tsur menuju Madinah. Rasulullah mencontohkan karakter keberanian dan ideologi yang teguh. Allah berfirman "Janganlah engkau bersedih hati, Allah selalu membersamai kita" (QS AtTaubah 9:40). Kekuatan ideologi mendasari keyakinan dan membawa ketenangan hati karena tertancap bahwa pembela, pengawal, dan penolong perjuangan hanya Allah SWT. Perjalanan hijrah mengajarkan pula dari peristiwa penunjukan pemandu jalan dari orang Yahudi yang bernama Abdullah bin Uraiqith al-Laitsi. Tauladan terbuka didapatkan dari buah pembelajaran hijrah bahwa kekuatan berbagai suku, bahasa, budaya, dan agama akan terbangun karakter positif. Komitmen, semangat membangun, rela berkorban, dan pantang mengkhianati bangsanya menjadi pembelajaran karakter hijrah Nabi. Karakter hidup dalam mensikapi pluralitas dan multikultural dicontohkan oleh kaum muhajirin. Sambutan terhadap kaum Anshor menunjukkan jiwa menghargai dan rasa persatuan, persaudaraan dan kebersamaan yang diutamakan. Semangat juang, loyalitas dan keyakinan dari buah kesadaran yang tertanam membuktikan peradaban Islam terbangun di Madinah. Tauladan Rasulullah tertanam melalui perjalanan hijrah bahwa kesulitan dan seberat apapun tantangan serta resiko kehidupan akan mudah dilalui dengan keteguhan pikiran, perasaan dan perilaku.

\section{KESIMPULAN}

Kegiatan penyuluhan yang bertemakan kontekstualisasi nilai-nilai hijrah Rasulullah sebagai penguatan karakter 'Aisyiyah dapat disarikan bahwa hijrah Nabi merupakan gerakan tajdid menuju kebangkitan Islam dari keterpurukan dan keterbelakangan yang dapat dijadikan acuan untuk mengambil pelajaran dalam gerakan 'Aisyiyah berkemajuan. Nilai-nilai karakter dari hijrah Nabi perlu diimplementasikan untuk penguatan karakter personal dan karakter sosial dalam melangkah menegakkan Islam yang sebenar-benarnya di muka bumi ini. Tindak lanjut dari kegiatan ini adalah setiap Ranting 'Aisyiyah melakukan kegiatan penyuluhan, sehingga ide-ide PP 'Aisyiyah secara sinergis sampai kepada semua anggota 'Aisyiyah.

\section{DAFTAR PUSTAKA}

Ambari, H.M., et.all, (1996). Ensiklopedi Islam. STIKES Dutagama Klaten: Ictiar Baru Van Hoeve.

Aswadi, (2011). Reformulasi Epistemologi Hijrah dalam Dakwah. Islamica, 5(2), 339-352.

Doni Koesoema A., (2010). Pendidikan Karakter, Jakarta: Grasindo.

Ibrohim, B., (2016). Memaknai Momentum Hijrah. Studia Didaktika. 10(2), 6574.

Kumalasari, D., (2018). Agama dan Budaya Sebagai Basis Pendidikan Karakter di Sekolah. Yogyakarta: Suluh Media.

Martin Lings, (1991). Mubammad Kisah Hidup Nabi Berdasarkan Sumber Klasik. Jakarta: Serambi. 
Marzuki. (2011). "Prinsip Dasar Pendidikan Karakter Perspektif Islam".Dalam buku Pendidikan Karakter, dalam Perspektif Teori dan Praktik. Yogyakarta: UNY Press.

Pedoman Kehidupan Islami Warga Muhammadiyah

Syarif \& Zuhri, S., (2019). Memahami hijrah dalam realitas alQuran dan Hadis Nabi Muhammad. Jurnal Living Hadis. 4(2), 277-307. 